\title{
Glucagon-like peptide-1 derived cardioprotection does not utilize a KATP-channel dependent pathway: mechanistic insights from human supply and demand ischemia studies
}

Joel P. Giblett ${ }^{1,2}$, Richard G. Axell ${ }^{3}$, Paul A. White ${ }^{3}$, Sophie J. Clarke², Liam McCormick' , Philip A. Read ${ }^{1}$, Johannes Reinhold ${ }^{2}$, Adam J. Brown ${ }^{1,2}$, Michael O'Sullivan' ${ }^{1}$ Nick E. J. West ${ }^{1}$, David P. Dutka ${ }^{2}$ and Stephen P. Hoole ${ }^{1^{*}}$

\begin{abstract}
Background: Glucagon-like peptide-1 (7-36) amide (GLP-1) protects against stunning and cumulative left ventricular dysfunction in humans. The mechanism remains uncertain but GLP-1 may act by opening mitochondrial K-ATP channels in a similar fashion to ischemic conditioning. We investigated whether blockade of K-ATP channels with glibenclamide abrogated the protective effect of GLP-1 in humans.
\end{abstract}

Methods: Thirty-two non-diabetic patients awaiting stenting of the left anterior descending artery (LAD) were allocated into 4 groups (control, glibenclamide, GLP-1, and GLP-1 + glibenclamide). Glibenclamide was given orally prior to the procedure. A left ventricular conductance catheter recorded pressure-volume loops during a 1-min low-pressure balloon occlusion (BO1) of the LAD. GLP-1 or saline was then infused for 30-min followed by a further 1-min balloon occlusion (BO2). In a non-invasive study, 10 non-diabetic patients were randomized to receive two dobutamine stress echocardiograms (DSE) during GLP-1 infusion with or without oral glibenclamide pretreatment.

Results: GLP-1 prevented stunning even with glibenclamide pretreatment; the $\Delta \% \mathrm{dP} / \mathrm{dt}_{\max } 30$-min post-BO1 normalized to baseline after GLP-1: $0.3 \pm 6.8 \%(p=0.02)$ and GLP-1 + glibenclamide: $-0.8 \pm 9.0 \%(p=0.04)$ compared to control: $-11.5 \pm 10.0 \%$. GLP-1 also reduced cumulative stunning after $\mathrm{BO}:-12.8 \pm 10.5 \%(p=0.02)$ as did GLP-1 + glibenclamide: $-14.9 \pm 9.2 \%(p=0.02)$ compared to control: $-25.7 \pm 9.6 \%$. Glibenclamide alone was no different to control. Glibenclamide pretreatment did not affect global or regional systolic function after GLP-1 at peak DSE stress (EF 74.6 \pm 6.4 vs. $74.0 \pm 8.0, p=0.76$ ) or recovery (EF 61.9 \pm 5.7 vs. $61.4 \pm 5.6, p=0.74$ ).

Conclusions: Glibenclamide pretreatment does not abrogate the protective effect of GLP-1 in human models of non-lethal myocardial ischemia.

Trial registration Clinicaltrials.gov Unique Identifier: NCT02128022

Keywords: Ischemia-reperfusion injury, Glucagon-like peptide-1, Cardioprotection, KATP

\footnotetext{
*Correspondence: s.hoole@nhs.net

1 Department of Interventional Cardiology, Papworth Hospital, Papworth

Everard, Cambridge CB23 3RE, UK

Full list of author information is available at the end of the article
} 


\section{Background}

Percutaneous coronary intervention (PCI) is the cornerstone of treatment for acute myocardial infarction (AMI) but ischemia-reperfusion (IR) injury may account for up to $50 \%$ of the final infarct size [1]. Adjunctive cardioprotective strategies to limit or prevent IR injury are desperately needed [2]. One strategy is ischemic conditioning (IC) in which repeated episodes of brief ischemia applied to a tissue protect against larger ischemic insults both locally and in distant tissues [3-5]. IC mediates cardioprotection through the opening of the mitochondrial K-ATP (mK-ATP) channel and closure of the mitochondrial permeability transition pore (mPTP) [6]. Blockade of mK-ATP with the sulfonylurea glibenclamide (glyburide) has been shown to abolish IC in humans [7, 8]. Sulfonylureas are important medications for the treatment of diabetes mellitus but they may cause an increase in cardiovascular mortality, perhaps as a result of interfering with protection from ischemic conditioning [9].

IC has proved challenging to translate into patient benefit so other strategies have focused on pharmacological agents to limit IR injury [2]. One promising agent is Glucagon-like peptide-1 (7-36) amide (GLP-1), an incretin hormone with an insulinotropic action, released from the gut in response to a food bolus [10]. Exogenous GLP-1 receptor agonists and drugs that inhibit its breakdown are used to treat type 2 diabetes mellitus. A beneficial off-target effect of GLP-1 is protection against IR injury [11-13]. GLP-1 abolishes PCI-induced left ventricular (LV) stunning (supply ischemia) [14, 15] and improves LV function during dobutamine stress echocardiography (demand ischemia) [16]. Evidence from animal studies suggests that GLP-1 may act through similar subcellular signaling pathways to IC $[17,18]$. We sought to establish whether blockade of mK-ATP would abolish the cardioprotection conferred by GLP-1 in human studies of both demand and supply ischemia.

\section{Methods}

\section{Study population}

Patients were aged over 18 years old and able to give informed consent. They had proximal left anterior descending artery (LAD) disease requiring PCI (supply protocol) or any coronary artery disease requiring revascularization (demand protocol). Patients were not enrolled in both studies. Exclusion criteria were presence of diabetes mellitus, use of nicorandil or ranolazine, a serum creatinine $>200 \mu \mathrm{mol} / \mathrm{l}$, presence of a cardiac pacemaker, valvular heart disease, impaired left ventricular systolic function, recent myocardial infarction or life expectancy less than 6-months.

\section{Ethics, consent and permissions}

Both protocols were approved by the local ethics committee (14/EE/0056 and 08/H0304/68) and informed, written consent was obtained from all participants before enrolment. Studies were carried out in accordance with institutional guidelines. The studies were registered on clinicaltrials.gov (NCT02128022) and ISRCTN (ISRCTN69686930) and were performed in accordance with the Declaration of Helsinki.

\section{Supply ischemia protocol}

A timeline for this protocol is shown in Fig. 1. Patients were fasted for $6 \mathrm{~h}$ prior to the procedure and received standard dual antiplatelet loading with aspirin and clopidogrel. Patients were allocated to one of four groups: saline control, GLP-1 alone, saline with glibenclamide and GLP-1 with glibenclamide. Patients received glibenclamide $5 \mathrm{mg}$ orally at least $60 \mathrm{~min}$ prior to their PCI procedure and had a dextrose $20 \%$ infusion initiated at $1.5 \mathrm{mg} / \mathrm{kg} / \mathrm{min}$ to minimize the risk of hypoglycemia. In mechanistic studies an oral dose of $5 \mathrm{mg}$ was sufficient to inhibit IC in humans [19].

Sheaths were placed in the right femoral artery, right radial artery and right femoral vein. Between 70 and $100 \mathrm{U} / \mathrm{kg}$ of unfractionated heparin was administered to maintain an activated coagulation time of $>250 \mathrm{~s}$ throughout the procedure. An 8-electrode 7F conductance catheter (Millar Instruments, Houston, USA) was connected to an MPVS Ultra (Millar Instruments, Houston, USA) signal-conditioning unit in series with an ADInstruments PowerLab 16/30 Series (ADInstruments, New South Wales, Australia) 16-channel amplifier. It was positioned along the longitudinal ventricular axis with the tip at the apex of the LV (Fig. 2). The conductance catheter was calibrated and corrected for parallel conductance $[14,20]$ as described in Additional file 1.

The left coronary ostium was intubated with a guide catheter and the lesion was crossed with a coronary guide wire. Baseline pressure-volume loops were recorded from the conductance catheter after the lesion was crossed (BL1) during a breath-hold in mid-expiration. Similarly, pressure-volume loops were recorded at the end of a 1-min low-pressure ( $<4$ atmospheres) coronary balloon inflation (BO1) within the lesion. Contrast was injected during balloon inflation to confirm coronary occlusion.

Patients randomized to receive GLP-1 then received an intravenous infusion of GLP-1 at $1.2 \mathrm{pmol} / \mathrm{kg} / \mathrm{min}$ started immediately after balloon deflation. This dose was selected as it had been effective in inducing cardioprotection in previous studies, with minimal side-effects [14]. Those patients in the control and glibenclamide only 


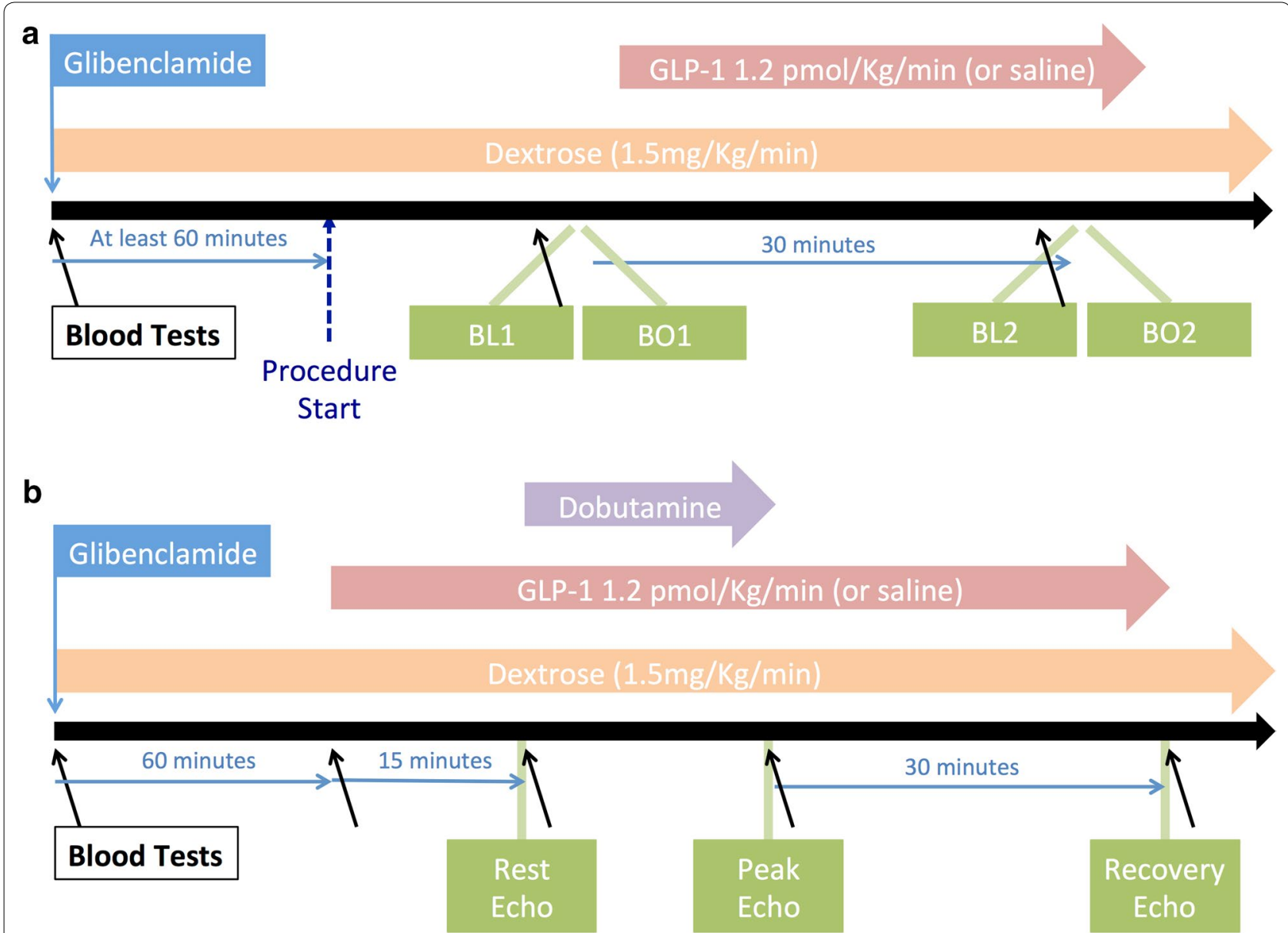

Fig. 1 Structure of supply and demand protocols. a Timeline for the supply ischemia protocol. Blood tests were taken immediately before the two balloon occlusions. GLP-1 was administered until BO2 was complete. b The study timeline for the demand ischemia protocol

groups received an infusion of normal saline at the same rate. After 30-min, further pressure-volume loops were collected (BL2) followed by recordings after a further 1-min balloon occlusion (BO2). Patients then received conventional coronary angioplasty and stenting of the lesion at the discretion of the treating physician. Oneminute balloon occlusions are long enough to induce ischemic dysfunction and stunning of the myocardium but will not activate the protective effect of ischemic conditioning [21].

\section{Pressure-volume loop analysis}

Conductance catheter data analysis was performed offline using LabChart (AdInstruments, New South Wales, Australia), by investigators blinded to treatment allocation. Five cardiac cycles recorded at each timepoint (BL1, BO1, BL2, BO2) were sampled (Fig. 2) and used to determine systolic parameters: $\mathrm{dP} / \mathrm{dt}_{\max }$ (maximum rate of isovolumic pressure increase), stroke volume and ejection fraction and diastolic parameters: $\mathrm{dP} /$ $\mathrm{dt}_{\min }$ (maximum rate of isovolumic pressure decline) and Tau (time constant of isovolumic pressure decline). Tau is calculated from the conductance catheter-derived $P_{t}$ (time constant of pressure relaxation) which is measured from the time of peak rate of pressure decline $\left(\mathrm{dP} / \mathrm{dt}_{\text {min }}\right)$ to $5 \mathrm{mmHg}$ above end-diastolic pressure.

\section{Demand ischemia protocol}

Patients underwent two dobutamine stress echocardiograms (DSE) in randomly allocated order, performed at least 1 week apart. Patients attended in the morning following an overnight fast and received a GLP-1 infusion with or without oral glibenclamide $5 \mathrm{mg}$ administered 60-min prior to the GLP-1 infusion. GLP-1 was started at $1.2 \mathrm{pmol} / \mathrm{kg} / \mathrm{min}$ followed by dobutamine administration 15 min later. An intravenous infusion of $20 \%$ dextrose started at $1.5 \mathrm{mg} / \mathrm{kg} / \mathrm{min}$ was given during both DSE to minimize the risk of glibenclamide-induced hypoglycaemia. Each patient acted as their own control. Intravenous dobutamine infusion was incrementally increased 


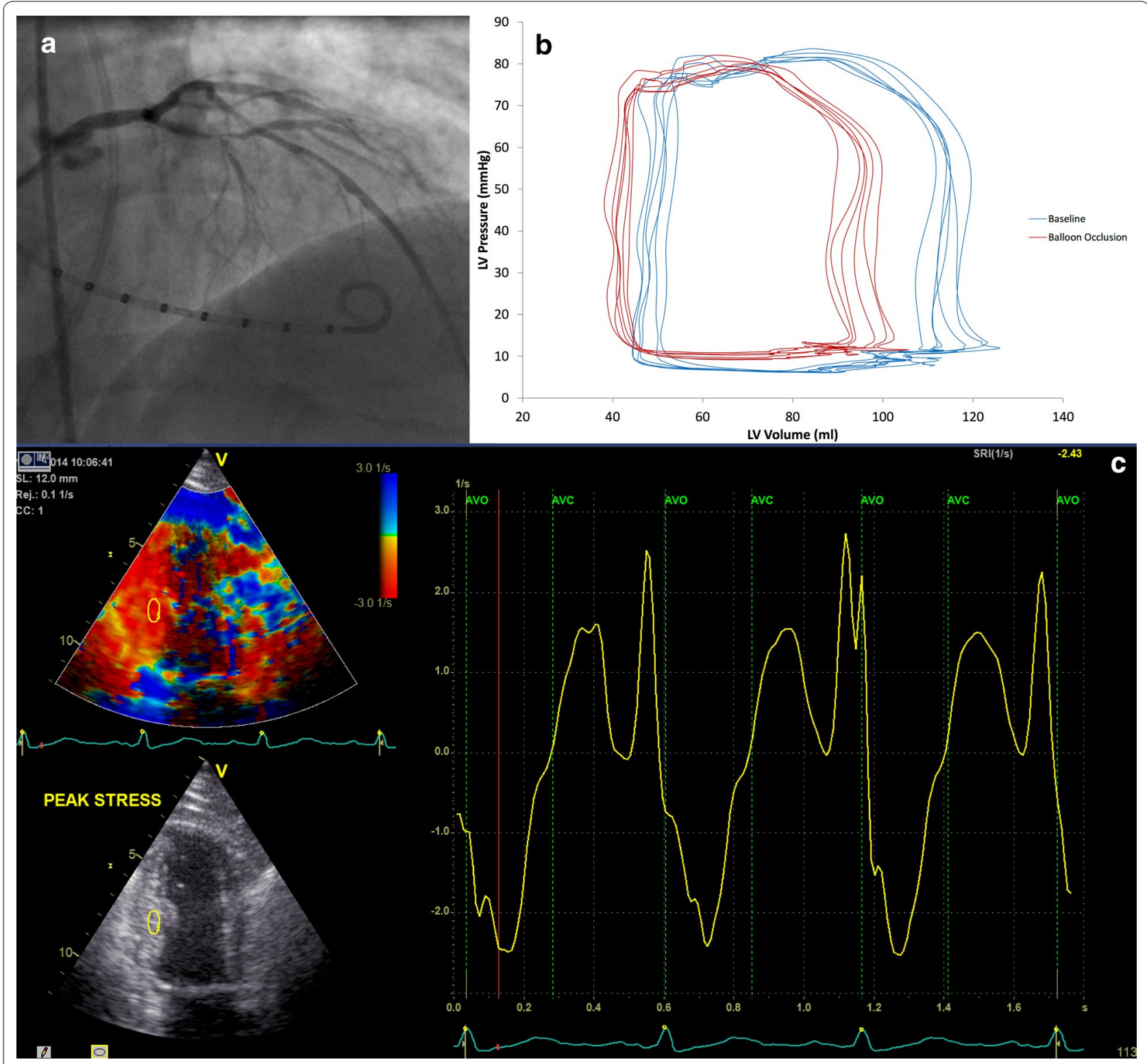

Fig. 2 Examples of methodology. a Conductance catheter in position in the left ventricle during an injection of contrast into the left coronary artery. The proximal LAD lesion can be seen. b Pressure-volume loops generated at baseline (blue) and during occlusion of the LAD (red). c Dobutamine stress echo at peak stress. Strain rate is shown to the right with the peak systolic strain rate the most negative point between aortic valve opening and closure

from $10 \mu \mathrm{g} / \mathrm{kg} / \mathrm{min}$ to 20,30 and $40 \mu \mathrm{g} / \mathrm{kg} / \mathrm{min}$ at $3-\mathrm{min}$ intervals. Up to $2 \mathrm{mg}$ of intravenous atropine could be given if necessary to reach the target heart rate. Both GLP-1 and dextrose infusions continued throughout the protocol until recovery was complete (Fig. 1). Criteria for stopping included, achievement of target heart rate (220 - Age * 0.85 BPM), angina, ischemic ECG changes (ST depression or elevation greater than $2 \mathrm{~mm}$ ), rise in systolic blood pressure to $>240 \mathrm{mmHg}$, fall in systolic blood pressure to $<100 \mathrm{mmHg}$ or severe arrhythmia.

\section{Transthoracic echocardiographic analysis}

Two-dimensional transthoracic tissue Doppler imaging (TDI) was performed in the left recumbent position at rest, peak stress and 30-min recovery. Images were recorded in 2, 3 and 4 chamber apical views allowing a 12-segment model (apical and mid segments) of regional wall motion to be assessed. Segments were classified as ischemic or non-ischemic according to whether or not they were subtended by a coronary stenosis $>70 \%$ by Quantitative Coronary Angiographic (QCA) analysis, 
as validated by Baptista et al. [22]. Relevant ischemicsegments were analyzed offline to determine the systolic tissue velocity (Vs), strain index (SI), and strain rate index (SRI) by a clinician blinded to treatment allocation (Fig. 2). Global left ventricular function was calculated by ejection fraction (EF) using Simpson's Biplane method and mitral annular systolic velocity (MASV) averaged from six sites. Inter-observer variability and intraobserver variability were assessed using images from three randomly selected patients. This was expressed as an Interclass Correlation Coefficient (ICC) with $95 \%$ confidence interval [23].

\section{Biochemistry}

During the supply ischemia protocol venous blood was sampled at baseline and immediately prior to $\mathrm{BO} 1$ and $\mathrm{BO} 2$. In the demand ischemia protocol venous blood was sampled prior to starting dextrose, GLP-1 and dobutamine infusions, at peak stress and at 30-minute recovery (Fig. 1).

GLP-1 (7-36) amide, free fatty acid, insulin and glucose levels were assayed. Samples for GLP-1 were drawn into tubes containing dipeptidyl peptidase 4 (DPP4) inhibitor (Millipore, UK) to prevent degradation and measured using a commercially available assay (Meso Scale Discovery, MD, USA). Glucose samples were measured by YSI 2300 STAT Plus analyzer (YSI Life Sciences, UK).

\section{Statistical analysis}

In the supply protocol a power calculation was carried out based on previous work by our group [14]. Analysis of non-diabetic patients who had previously received saline or GLP-1 infusion after a balloon occlusion in a similar protocol to this study had a delta $\mathrm{dP} / \mathrm{dt}_{\max }$ at BL2 of $-13.4 \pm 9.3 \%$ and $-1.4 \pm 8.5 \%$ respectively. We estimated that to detect a difference of $8 \%$ at BL2 $(\alpha=0.05$, $\beta=0.2$ ) a sample size of 8 per group was required.

In the demand ischemia protocol, previous data has shown that a GLP-1 infusion caused an additional increase in ejection fraction at peak stress from $70.8 \pm 4.96$ to $77.0 \pm 4.39 \%$ in a paired study [16]. We estimated that to detect a $5 \%$ change in ejection fraction a sample size of 7 patients were needed $(\alpha=0.05, \beta=0.2)$.

All analyses were pre-specified. Continuous data are presented as mean \pm SD unless otherwise stated. Paired and unpaired Student's t test or Mann-Whitney U test were used to compare continuous variables as appropriate, and Chi Square test was used for categorical variables. In the supply ischemia study, 4-way comparisons between groups were carried out with a one-way independent ANOVA. A p value of $<0.05$ was deemed statistically significant.

\section{Results}

\section{Supply ischemia protocol}

Thirty-three patients were recruited into the 4 groups detailed above (Additional file 1: Figure S1). In one case the operator was unable to cross the aortic valve with the conductance catheter and this patient was excluded. Demographic details for the groups are summarized in Additional file 1: Table S1 and confirm that they were well matched.

Biochemistry data is summarized in Table 1 . Levels of plasma GLP-1 (7-36) amide were below $3.0 \mathrm{pg} / \mathrm{ml}$ at baseline and during $\mathrm{BO} 1$ confirming no significant difference between groups. Plasma levels of GLP-1 (7-36) amide rose at $\mathrm{BO} 2$ in groups treated with GLP-1 compared with those administered only saline, with no significant difference between the GLP-1-treated groups $(p=0.41)$. Plasma levels of insulin were significantly elevated at $\mathrm{BO} 2$ in patients treated with glibenclamide and the combination of GLP-1 and glibenclamide caused an even greater rise although the response was highly variable between individuals. Patients treated with glibenclamide also had significant suppression of free fatty acids at $\mathrm{BO} 1$ and $\mathrm{BO} 2$. Plasma glucose levels were higher at $\mathrm{BO} 2$ in glibenclamide treated groups, compared with control, despite the rise in insulin levels, reflecting the co-administration of dextrose alongside glibenclamide.

There were no significant differences between the baseline hemodynamic parameters of groups (Additional file 1: Table S2). Table 2 describes how parameters of systolic and diastolic function change during the supply ischemia protocol for each group. All groups suffered ischemic LV dysfunction during BO1 compared to BL1, with a significant deterioration in all measured parameters of systolic and diastolic function. There was no significant difference between any groups at BO1. At BL2 there was recovery of $\mathrm{dP} / \mathrm{dt}_{\max }$ and $\mathrm{dP} / \mathrm{dt}_{\min }$ to BL1 levels in both GLP-1 treated groups. There was impaired recovery of $\mathrm{dP} / \mathrm{dt}_{\max }$ and $\mathrm{dP} / \mathrm{dt}_{\min }$ in control and glibenclamide only groups with significant stunning compared with BL1. Glibenclamide had a neutral effect on systolic and diastolic function during balloon occlusion and recovery.

Cumulative stunning after the second balloon occlusion was only observed in groups not receiving GLP-1; systolic and diastolic function did not deteriorate below the level observed at BO1 in GLP-1 treated groups. Change in $\mathrm{dP} / \mathrm{dt}_{\max }$ (Fig. 3) and $\mathrm{dP} / \mathrm{dt}_{\min }$ (Fig. 4) are shown for each group at the specified time points. GLP-1 infusion also improved $\mathrm{EF}$ at $\mathrm{BL} 2$ and $\mathrm{BO} 2$ compared to control although this was only statistically significant at BO2. Tau appeared to improve with GLP-1 but this was not statistically significant. There was no significant change in heart rate $(\mathrm{p}=0.14)$ or mean arterial pressure 
Table 1 Metabolic changes during supply ischemia protocol

\begin{tabular}{|c|c|c|c|c|c|c|}
\hline & Baseline & & Balloon occl & (BO1) & Balloon occlu & $\mathrm{BO} 2)$ \\
\hline & & p value* & & p value* & & $p$ value* \\
\hline GLP-1 (7-36) amide, pg & & & & & & \\
\hline Control & $2.9 \pm 3.57$ & - & $3.6 \pm 4.13$ & - & $2.9 \pm 1.84$ & - \\
\hline GLP-1 only & $2.8 \pm 1.43$ & 0.51 & $2.5 \pm 2.04$ & 0.49 & $87.5 \pm 37.1$ & $<0.001$ \\
\hline Glibenclamide only & $1.9 \pm 1.66$ & 0.46 & $1.1 \pm 0.77$ & 0.11 & $1.3 \pm 0.54$ & 0.07 \\
\hline GLP-1 glibenclamide & $2.2 \pm 0.59$ & 0.57 & $2.3 \pm 1.32$ & 0.37 & $78.9 \pm 31.1$ & $<0.001$ \\
\hline Insulin, pmol/L & & & & & & \\
\hline Control & $79 \pm 26$ & - & $59 \pm 29$ & - & $58 \pm 29$ & - \\
\hline GLP-1 only & $77 \pm 52$ & 0.91 & $63 \pm 85$ & 0.82 & $95 \pm 64$ & 0.16 \\
\hline Glibenclamide only & $103 \pm 93$ & 0.51 & $292 \pm 245$ & 0.02 & $382 \pm 297$ & 0.02 \\
\hline GLP-1 glibenclamide & $90 \pm 51$ & 0.63 & $412 \pm 244$ & $<0.01$ & $1133 \pm 1089$ & 0.03 \\
\hline Glucose, $\mathrm{mmol} / \mathrm{l}$ & & & & & & \\
\hline Control & $5.1 \pm 0.3$ & - & $5.3 \pm 0.3$ & - & $5.4 \pm 0.4$ & - \\
\hline GLP-1 only & $5.0 \pm 0.3$ & 0.83 & $5.0 \pm 0.3$ & 0.51 & $4.7 \pm 0.3$ & 0.20 \\
\hline Glibenclamide only & $5.3 \pm 0.3$ & 0.66 & $6.3 \pm 0.4$ & 0.06 & $6.8 \pm 0.4$ & 0.02 \\
\hline GLP-1 glibenclamide & $5.5 \pm 0.3$ & 0.44 & $5.9 \pm 0.4$ & 0.27 & $5.9 \pm 0.7$ & 0.45 \\
\hline Free fatty acids, $\mu \mathrm{mol} / \mathrm{L}$ & & & & & & \\
\hline Control & $371 \pm 364$ & - & $1399 \pm 973$ & - & $1050 \pm 637$ & - \\
\hline GLP-1 only & $473 \pm 367$ & 0.57 & $1213 \pm 897$ & 0.69 & $917 \pm 516$ & 0.64 \\
\hline Glibenclamide only & $358 \pm 201$ & 0.93 & $633 \pm 434$ & 0.06 & $439 \pm 248$ & 0.02 \\
\hline GLP-1 glibenclamide & $356 \pm 183$ & 0.91 & $846 \pm 490$ & 0.16 & $503 \pm 307$ & 0.04 \\
\hline Dextrose infusion, mg k & & & & & & \\
\hline Glibenclamide only & - & - & $1.69 \pm 0.53$ & - & $1.69 \pm 0.53$ & - \\
\hline GLP-1 glibenclamide & - & - & $2.25 \pm 1.6$ & - & $2.44 \pm 1.59$ & - \\
\hline
\end{tabular}

* p value compared with control group

$(\mathrm{p}=0.67)$ between balloon occlusions, or between individual groups.

\section{Demand ischemia protocol}

Ten patients were recruited into the demand ischemia protocol. Two patients did not go on to have both DSE (one patient withdrew and one needed urgent revascularization prior to second DSE). Detailed demographic data are summarized in the Additional file 1: Table S3.

Overall there were no significant differences in hemodynamic parameters between the DSE. Importantly, GLP-1 infusion did not increase heart rate during the 15 min prior to the DSE in the GLP-1 only DSE ( $57 \pm 3.8$ vs. $58 \pm 3.9, \mathrm{p}=0.44)$. There was no significant difference in the RPP at peak stress between the DSE. These data are summarized in Additional file 1: Table S4.

There was a rise in GLP-1 levels at peak stress during both DSE of over 50-fold compared with pre-DSE levels. Insulin levels rose in both DSE but were twice as high for the GLP-1 + glibenclamide group ( $\mathrm{p}=0.04)$. There was increased suppression of free fatty acids with GLP + glibenclamide. Biochemistry data for the demand ischemia protocol are summarized in Additional file 1: Table S5.
There was no difference in global indices of systolic function between the paired DSE at either peak stress or recovery, indicating that glibenclamide did not attenuate the effect of GLP-1 (Table 3). Regional tissue Doppler indices were also unchanged when ischemic segments alone, and all segments together were analyzed (Additional file 1: Table S6). Changes in the global and regional tissue Doppler indices are shown in Fig. 5. The ICC for inter- and intra-observer variability respectively was $0.899(0.850-0.931)$ and $0.922(0.863-0.975)$ for Vs; $0.802(0.698-0.873)$ and $0.831(0.748-0.886)$ for SI; 0.817 $(0.637-0.908)$ and $0.844(0.691-0.901)$ for SRI.

\section{Discussion}

In both the supply and demand ischemia protocols, addition of glibenclamide did not affect GLP-1 cardioprotection; GLP-1 protection against both ischemic left ventricular dysfunction and stunning remained. The implication of this study is that GLP-1 cardioprotection is not mediated through mK-ATP dependent pathways. Similar metabolic profiles (between glibenclamidetreated groups) ruled-out a metabolic explanation for the cardioprotection observed. Only the presence or 
Table 2 Change in parameters of systolic and diastolic function (compared to BL1) in supply ischemia protocol

\begin{tabular}{|c|c|c|c|c|c|c|c|}
\hline & Baseline 1 (BL1) & Balloon occlu & 1 (BO1) & Baseline 2 (B & & Balloon occlu & 2 (BO2) \\
\hline & $\%$ & $\Delta \%$ & p value* & $\Delta \%$ & p value* & $\Delta \%$ & $\begin{array}{l}\mathrm{p} \\
\text { value* }\end{array}$ \\
\hline $\mathrm{dP} / \mathrm{dt}_{\max }$ & & & & & & & \\
\hline Control & 100 & $-15.4 \pm 13.6$ & 0.012 & $-11.5 \pm 10.0$ & $<0.01$ & $-25.7 \pm 9.6$ & $<0.001$ \\
\hline GLP-1 only & 100 & $-16.1 \pm 10.2$ & $<0.01$ & $-0.3 \pm 6.8$ & 0.92 & $-12.8 \pm 10.5$ & 0.011 \\
\hline Glibenclamide only & 100 & $-16.1 \pm 14.4$ & 0.011 & $-10.0 \pm 4.7$ & $<0.01$ & $-21.7 \pm 10.5$ & $<0.01$ \\
\hline GLP-1 glibenclamide & 100 & $-13.5 \pm 9.7$ & $<0.01$ & $-0.8 \pm 9.0$ & 0.82 & $-14.9 \pm 9.2$ & $<0.01$ \\
\hline Ejection fraction & & & & & & & \\
\hline Control & 100 & $-18.3 \pm 14.1$ & 0.01 & $-13.8 \pm 15.5$ & 0.03 & $-31.1 \pm 16.0$ & $<0.001$ \\
\hline GLP-1 only & 100 & $-17.9 \pm 13.3$ & 0.01 & $-8.4 \pm 12.7$ & 0.10 & $-11.7 \pm 17.8$ & 0.10 \\
\hline Glibenclamide only & 100 & $-17.2 \pm 13.4$ & 0.01 & $-12.7 \pm 19.6$ & 0.14 & $-26.9 \pm 14.2$ & $<0.001$ \\
\hline GLP-1 glibenclamide & 100 & $-16.9 \pm 13.8$ & 0.01 & $-8.4 \pm 4.8$ & $<0.01$ & $-13.1 \pm 9.5$ & $<0.01$ \\
\hline Stroke volume & & & & & & & \\
\hline Control & 100 & $-19.6 \pm 18.1$ & 0.03 & $-16.4 \pm 16.3$ & 0.02 & $-31.2 \pm 16.6$ & $<0.001$ \\
\hline GLP-1 only & 100 & $-19.8 \pm 17.5$ & 0.01 & $-5.8 \pm 27.1$ & 0.56 & $-12.6 \pm 28.8$ & 0.26 \\
\hline Glibenclamide only & 100 & $-16.8 \pm 17.8$ & 0.08 & $-12.6 \pm 18.2$ & 0.12 & $-23.2 \pm 22.1$ & 0.04 \\
\hline GLP-1 glibenclamide & 100 & $-14.8 \pm 11.1$ & 0.01 & $-0.2 \pm 7.3$ & 0.96 & $-5.6 \pm 4.4$ & 0.03 \\
\hline $\mathrm{dP} / \mathrm{dt}_{\min }$ & & & & & & & \\
\hline Control & 100 & $-25.1 \pm 14.7$ & $<0.01$ & $-10.9 \pm 4.7$ & $<0.001$ & $-33.3 \pm 8.6$ & $<0.001$ \\
\hline GLP-1 only & 100 & $-21.3 \pm 8.3$ & $<0.001$ & $+5.0 \pm 11.6$ & 0.26 & $-21.3 \pm 8.7$ & 0.04 \\
\hline Glibenclamide only & 100 & $-26.4 \pm 14.3$ & $<0.001$ & $-7.1 \pm 12.5$ & 0.17 & $-28.6 \pm 13.1$ & $<0.001$ \\
\hline GLP-1 glibenclamide & 100 & $-19.6 \pm 6.1$ & $<0.001$ & $+2.9 \pm 13.0$ & 0.55 & $-14.3 \pm 13.6$ & 0.02 \\
\hline Tau & & & & & & & \\
\hline Control & 100 & $+34.7 \pm 16.9$ & $<0.01$ & $+12.7 \pm 7.8$ & $<0.01$ & $+46.4 \pm 15.4$ & $<0.001$ \\
\hline GLP-1 only & 100 & $+27.3 \pm 11.6$ & $<0.001$ & $+8.0 \pm 18.6$ & 0.26 & $+31.0 \pm 36.7$ & 0.05 \\
\hline Glibenclamide only & 100 & $+30.5 \pm 25.8$ & $<0.01$ & $+13.1 \pm 19.9$ & 0.14 & $+36.2 \pm 26.3$ & $<0.001$ \\
\hline GLP-1 glibenclamide & 100 & $+31.3 \pm 27.2$ & $<0.001$ & $+5.5 \pm 10.2$ & 0.17 & $32.5 \pm 13.2$ & $<0.001$ \\
\hline
\end{tabular}

* $p$ value compared to BL1 for each group

absence of GLP-1 appeared to be associated with a protective effect and this was independent of both mK-ATP blockade and changes in myocardial substrate and insulin levels.

IC acts via mK-ATP-dependent subcellular signaling pathway that is activated by up-stream RISK/SAFE pathways of cardioprotection [11, 18]. IC protection from non-lethal endothelial IR injury has been shown to be K-ATP dependent in humans. This protection is blocked with glibenclamide [8]. Although IC has not been shown to protect against stunning or ischemic dysfunction in humans [24], GLP-1 does protect the LV against this model of non-lethal IR injury, as confirmed in this study. The current study also shows that co-administration of glibenclamide with GLP-1 does not affect GLP-1 cardioprotection. Therefore cardioprotection against non-lethal IR injury by GLP-1 is not mediated through mK-ATP dependent subcellular signaling pathways in humans. This is surprising since a number of other studies suggest K-ATP dependent signaling pathways mediate the actions of GLP-1 on the vasculature. K-ATP channels are involved in GLP-1 dependent relaxation of the aorta in a rat model, and endothelial function in human forearms $[17,25]$. Animal studies have shown that phosphoinositol-3 kinase (PI3K) and Akt are consistently activated during treatment with GLP-1 $[11,18,26]$. Our study suggests that either human GLP-1 cardioprotection is mediated through an alternative pathway, or that PI3K-Akt signaling acts through an alternative mechanism to protect against myocardial stunning and ischemic dysfunction. There is considerable cross-talk in the RISK/SAFE pathways and it may be that these kinases are acting on an alternative distal target [27]. Since evidence suggests that the known GLP-1 receptor is not present on the human ventricular cardiomyocyte [28], GLP-1 may act remote to the myocardium or by binding an as yet unidentified receptor.

In the supply protocol both glibenclamide alone and GLP-1 alone produced a rise in insulin levels and a fall in free fatty acids compared to saline control. However, 


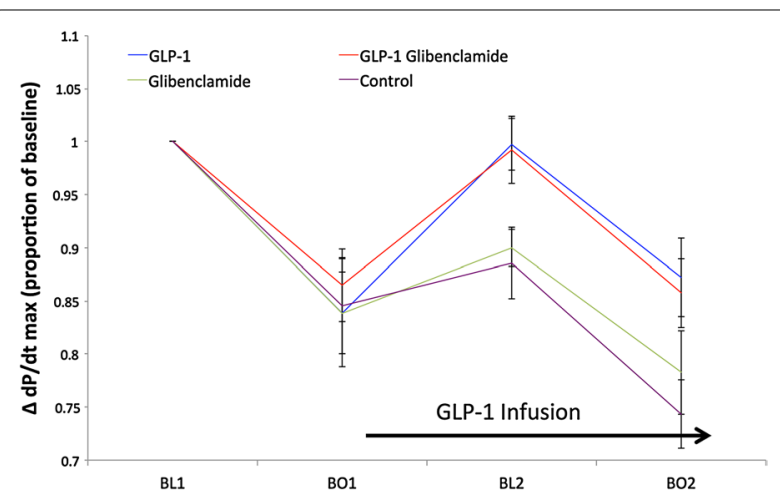

Fig. 3 Systolic function $\left(\Delta d P / d t_{\max }\right)$ in supply ischemia protocol. Mean $\pm \mathrm{SEM}$. There were no statistically significant differences between groups at BO1. At BL2, dP/dt max for GLP-1 was significantly improved compared to control $(p=0.02)$ and compared to glibenclamide alone $(p<0.01)$. This difference was maintained for comparison with control at $\mathrm{BO} 2(\mathrm{p}=0.02)$ and was numerically better than glibenclamide at $\mathrm{BO} 2(p=0.12)$. $\mathrm{dP} / \mathrm{dt}_{\max }$ for GLP-1 + glibenclamide was significantly improved at BL2 compared to control $(p=0.02)$ and glibenclamide alone $(p=0.03)$. Again this difference was maintained for comparison with control at $\mathrm{BO} 2(\mathrm{p}=0.02)$ and trended towards improvement for glibenclamide alone at $\mathrm{BO} 2(p=0.14)$. There was no statistically significant difference between GLP-1 treated groups, nor any difference between the control and glibenclamide only groups, at any timepoint

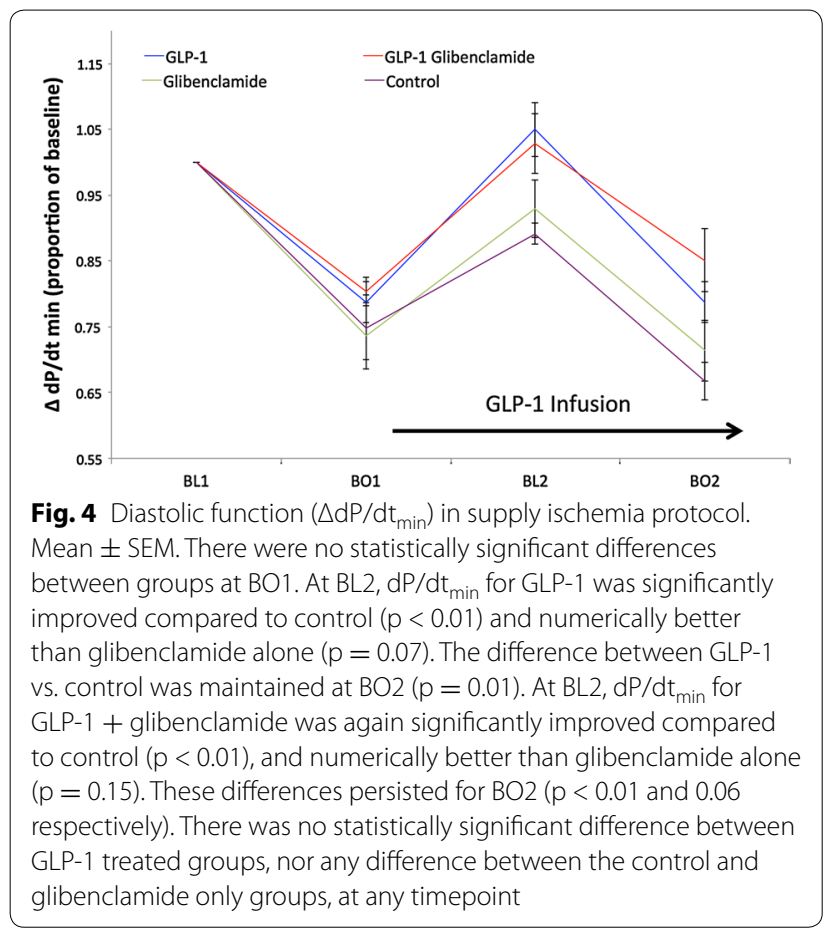

only GLP-1 had a cardioprotective effect. Glibenclamide only produced changes in metabolic parameters without an observed difference in the function of the ventricle
Table 3 Change in parameters of global systolic function, and ischemic regional segments in demand ischemia protocol

\begin{tabular}{|c|c|c|c|}
\hline & GLP-1 only & GLP-1 glibenclamide & $\mathrm{p}$ value \\
\hline \multicolumn{4}{|c|}{ Ejection fraction (\%) } \\
\hline Baseline & $62.4 \pm 8.4$ & $63.1 \pm 8.5$ & 0.45 \\
\hline Peak stress & $74.6 \pm 6.4$ & $74.0 \pm 8.1$ & 0.76 \\
\hline Recovery & $61.9 \pm 5.7$ & $61.4 \pm 5.6$ & 0.74 \\
\hline \multicolumn{4}{|l|}{ MASV, $\mathrm{cm} / \mathrm{s}$} \\
\hline Baseline & $5.47 \pm 1.79$ & $5.51 \pm 1.78$ & 0.82 \\
\hline Peak stress & $11.40 \pm 2.69$ & $11.06 \pm 2.80$ & 0.24 \\
\hline Recovery & $5.70 \pm 1.99$ & $5.62 \pm 1.75$ & 0.51 \\
\hline \multicolumn{4}{|c|}{ Peak systolic velocity (Vs), cm/s } \\
\hline Baseline & $3.76 \pm 1.89$ & $3.92 \pm 2.07$ & 0.38 \\
\hline Peak stress & $9.86 \pm 3.08$ & $9.59 \pm 2.81$ & 0.18 \\
\hline Recovery & $3.95 \pm 1.95$ & $4.04 \pm 1.56$ & 0.98 \\
\hline \multicolumn{4}{|c|}{ Strain index (SI), \% } \\
\hline Baseline & $-15.3 \pm 5.83$ & $-15.1 \pm 5.30$ & 0.68 \\
\hline Peak stress & $-15.5 \pm 5.52$ & $-15.6 \pm 6.09$ & 0.92 \\
\hline Recovery & $-14.8 \pm 5.35$ & $-15.3 \pm 6.21$ & 0.48 \\
\hline \multicolumn{4}{|c|}{ Strain rate index (SRI), s-1 } \\
\hline Baseline & $-1.19 \pm 0.74$ & $-1.25 \pm 0.51$ & 0.29 \\
\hline Peak stress & $-2.68 \pm 1.69$ & $-2.79 \pm 1.17$ & 0.65 \\
\hline Recovery & $-1.24 \pm 0.92$ & $-1.25 \pm 0.69$ & 0.71 \\
\hline
\end{tabular}

compared to control-this suggests that the metabolic effect of glibenclamide does not lead to alteration in cardiac function in this model. The combination of GLP-1 and glibenclamide produced even greater hyperinsulinemia but offered no additional protection beyond that of GLP-1 alone. Insulin levels with glibenclamide were similar to those observed during hyperinsulinemic clamp studies published by our group, which also showed a neutral effect of insulin on myocardial performance during ischemia [29]. It has been suggested that the mechanism for GLP-1 cardioprotection is a switch in cardiomyocyte metabolism towards more energy efficient myocardial glucose utilization [30]. Glibenclamide is insulinotropic through blockade of K-ATP on the pancreatic beta cell. The metabolic environment created with addition of glibenclamide and dextrose (increased availability of glucose, reduced availability of fatty acids and increased cellular uptake of glucose driven by hyperinsulinemia) should promote increased myocardial glucose utilization. However this environment did not result in cardioprotection without GLP-1, nor did it enhance cardioprotection beyond giving GLP-1 alone. These findings are consistent with our earlier human work, which did not detect a change in transmyocardial substrate utilization after GLP-1 infusion [15]. Taken as a whole, it seems unlikely that GLP-1 cardioprotection is mediated 


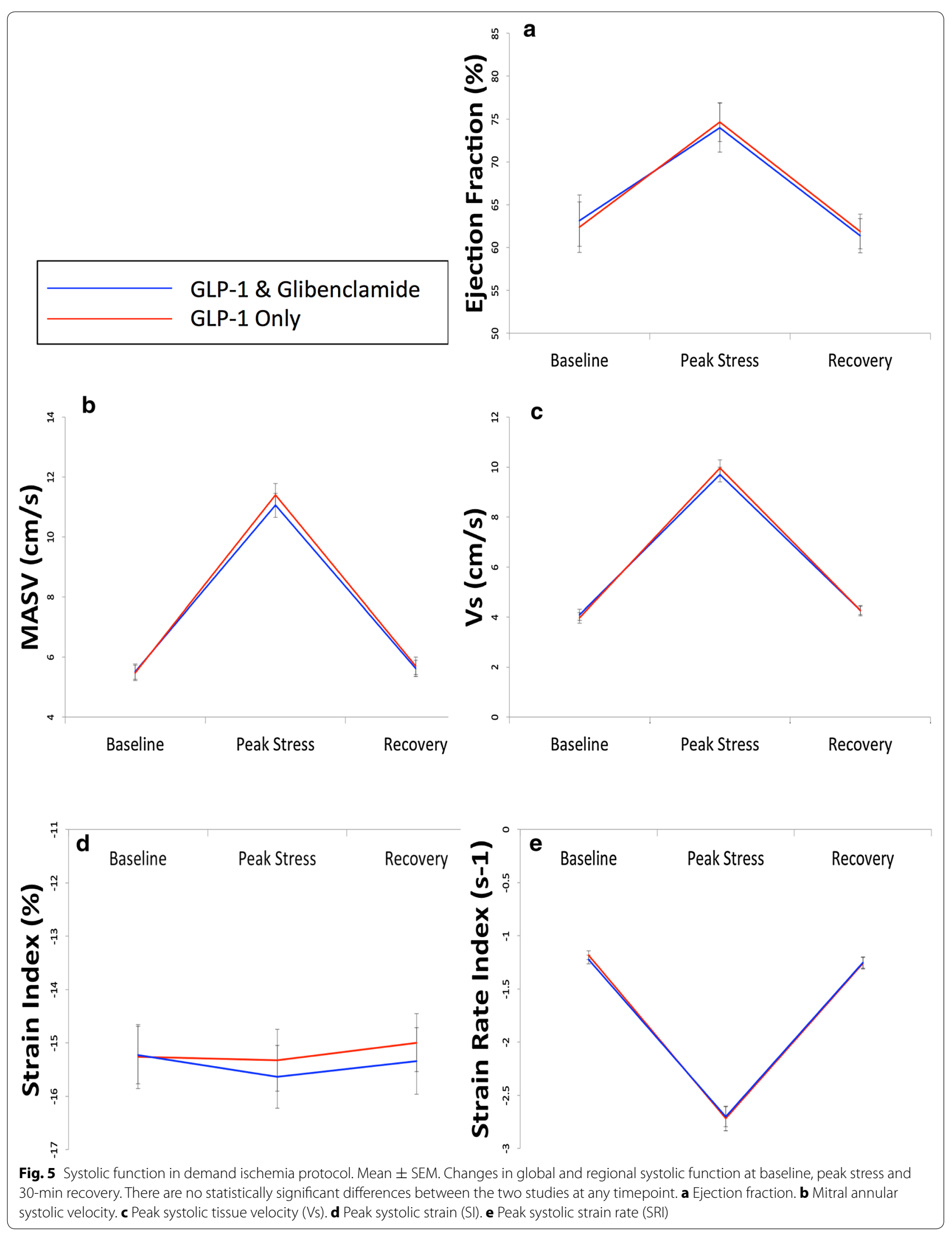


by straight-forward metabolic switching toward glucose metabolism or by change in insulin levels.

Studies have suggested that, in the human heart, the GLP-1 receptor is only present in the sinoatrial node [28]. GLP-1 receptor agonists such as Exenatide have been shown to increase heart rate [31]. In this study, the GLP-1 infusion did not affect heart rate. Since GLP-1 did not affect heart rate, or afterload and the peak rate pressure product achieved, there was no evidence from this study that GLP-1 protection was mediated through an effect on the peripheral vasculature reducing cardiac workload. Further work to confirm this is needed.

The mechanism underlying GLP-1 cardioprotection in non-lethal IR injury remains speculative. Animal evidence of mK-ATP dependent protection may still be applicable to lethal IR injury in humans. Alternatively, mK-ATP independent aspects of subcellular pro-survival kinase pathways may be involved in GLP-1 cardioprotection. Studies have suggested that adenosine may mediate some of the observed GLP-1 effects [32]. Adenosine released from remote endothelial cells in response to GLP-1 receptor binding may elicit an inotropic effect by inducing hyperemia, or alternatively by a direct protective effects on cardiomyocytes [33]. Evidence of effects independent of the known GLP-1 receptor pathway have also been described $[18,34,35]$ and GLP-1 may activate as yet unknown subcellular signaling pathways to confer protection. The protection offered involved native GLP-1 rather than a stable GLP-1 receptor agonist such as Exenatide. This may mean that breakdown products such as GLP-1 (9-36) amide may be responsible for some of the observed cardioprotection. GLP-1 (9-36) has been implicated in cardioprotection in some animal studies $[34,35]$. A number of other protective effects of GLP-1 have been explored. These include effects on platelet aggregation and thrombosis [36], and anti-inflammatory effects [37]. Whilst these effects may be important in protection against, and recovery from myocardial infarction, they are unlikely to explain the protection conferred against myocardial stunning.

\section{Limitations}

The study does not present direct evidence of blockade of the cardiomyocyte mK-ATP channel. This was assumed on the basis of previous studies [19]. It may also be inferred in this study as the insulinotropic effect of glibenclamide on the pancreatic beta cell (which was seen in the biochemical results) is dependent on sarcoplasmic K-ATP blockade [38]. This insulinotropic effect of glibenclamide necessitated the co-administration of dextrose to prevent hypoglycemia. Whilst the analyses suggest that this has not affected our conclusions, it is not possible to completely exclude some confounding effect.
The supply ischemia protocol did not measure loadindependent indices of ventricular function such as the end-systolic pressure volume relationship (Ees) due to the difficulty of simultaneously recording a family of pressure-volume loops during preload reduction (IVC balloon occlusion) whilst also balloon occluding the coronary artery. However, blood pressure and heart rate remained constant during the procedure allowing valid comparison of the load-dependent parameters studied. Whilst it would also have been statistically preferable to enroll a larger number of patients, ethical and practical considerations limited numbers to those specified in the power calculation.

In the demand ischemia protocol it would have been preferable to perform prospectively recruited saline and glibenclamide only DSEs to control comprehensively. This was not possible for both ethical and practical reasons. We instead relied upon our historic control data using the same protocol, which has demonstrated that GLP-1 augments myocardial performance during demand ischemia [16].

\section{Conclusion}

The cardioprotective effect of GLP-1 (7-36) amide in non-lethal IR ventricular injury does not appear to be mediated through an mK-ATP dependent pathway. Changes in myocyte substrate utilization and workload after GLP-1 also fail to explain the protection observed. Future mechanistic studies need to consider alternative mechanisms to explain the beneficial effect of GLP-1.

\section{Additional file}

Additional file 1. Additional material.

\section{Abbreviations}

AMI: acute myocardial infarction; BL1: baseline 1; BL2: baseline 2; BO1: balloon occlusion 1; BO2: balloon occlusion 2; DSE: dobutamine stress echocardiogram(s); EDP: end diastolic pressure; EF: ejection fraction; GLP-1: glucagon-like peptide 1 (7-36) amide; ICC: intra-class correlation coefficient; IPC: ischemic preconditioning; IR: ischemia-reperfusion; LAD: left anterior descending artery; LCX: left circumflex artery; LV: left ventricle; MASV: mitral annular systolic velocity; mK-ATP: mitochondrial K-ATP channel; PCl: percutaneous coronary intervention; RCA: right coronary artery; SV: stroke volume.

\section{Authors' contributions}

JPG, SJC, PAR, LM, DPD and SPH contributed to the conception of the study. JPG, RGA and PAW undertook analysis of the conductance catheter data. JPG and JR undertook acquisition and analysis of the stress echocardiography data. AJB, MOS, NEJW and SPH undertook the conductance catheter studies. JPG, SJC, PAR, LM, AJB, DPD and SPH contributed to interpretation of the data. All authors were involved in drafting and critical review of the final manuscript. All authors read and approved the final manuscript.

\section{Author details}

${ }^{1}$ Department of Interventional Cardiology, Papworth Hospital, Papworth Everard, Cambridge CB23 3RE, UK. ${ }^{2}$ Department of Cardiovascular Medicine, 
University of Cambridge, Cambridge, UK. ${ }^{3}$ Department of Clinical Engineering, Addenbrooke's Hospital, Cambridge, UK.

\section{Acknowledgements}

The authors are grateful to the staff and patients of Papworth Hospital and the Wellcome Trust Clinical Research Facility for their assistance with this research.

\section{Competing interests}

Sophie J. Clarke is an employee of Merck, Sharpe and Dohme. No other authors have any competing interests to declare.

\section{Funding}

This work was funded through the NIHR Biomedical Research Centre at the University of Cambridge.

Received: 28 May 2016 Accepted: 30 June 2016

Published online: 19 July 2016

\section{References}

1. Yellon DM, Hausenloy DJ. Myocardial reperfusion injury. N Engl J Med. 2007;357(11):1121-35.

2. Giblett JP, West NE, Hoole SP. Cardioprotection for percutaneous coronary intervention-reperfusion quality as well as quantity. Int J Cardiol. 2014;177(3):786-93.

3. Murry CE, Jennings RB, Reimer KA. Preconditioning with ischemia: a delay of lethal cell injury in ischemic myocardium. Circulation. 1986;74(5):1124-36.

4. Botker HE, Kharbanda R, Schmidt MR, Bottcher M, Kaltoft AK, Terkelsen CJ, Munk K, Andersen NH, Hansen TM, Trautner S, et al. Remote ischaemic conditioning before hospital admission, as a complement to angioplasty, and effect on myocardial salvage in patients with acute myocardial infarction: a randomised trial. Lancet. 2010;375(9716):727-34.

5. Hoole SP, Heck PM, Sharples L, Khan SN, Duehmke R, Densem CG, Clarke SC, Shapiro LM, Schofield PM, O'Sullivan M, et al. Cardiac remote ischemic preconditioning in coronary stenting (CRISP Stent) study: a prospective, randomized control trial. Circulation. 2009;119(6):820-7.

6. Kharbanda RK, Nielsen TT, Redington AN. Translation of remote ischaemic preconditioning into clinical practice. Lancet. 2009;374(9700):1557-65.

7. Kristiansen SB, Henning O, Kharbanda RK, Nielsen-Kudsk JE, Schmidt MR, Redington AN, Nielsen TT, Botker HE. Remote preconditioning reduces ischemic injury in the explanted heart by a KATP channel-dependent mechanism. Am J Physiol Heart Circ Physiol. 2005;288(3):H1252-6.

8. Tomai F, Crea F, Gaspardone A, Versaci F, De Paulis R, Penta de Peppo A, Chiariello L, Gioffre PA. Ischemic preconditioning during coronary angioplasty is prevented by glibenclamide, a selective ATP-sensitive K + channel blocker. Circulation. 1994:90(2):700-5.

9. Varga ZV, Ferdinandy P, Liaudet L, Pacher P. Drug-induced mitochondrial dysfunction and cardiotoxicity. Am J Physiol Heart Circ Physiol. 2015;309(9):H1453-67.

10. Holst JJ. The physiology of glucagon-like peptide 1. Physiol Rev. 2007:87(4):1409-39.

11. Bose AK, Mocanu MM, Carr RD, Brand CL, Yellon DM. Glucagon-like peptide 1 can directly protect the heart against ischemia/reperfusion injury. Diabetes. 2005;54(1):146-51

12. Nikolaidis LA, Doverspike A, Hentosz T, Zourelias L, Shen YT, Elahi D, Shannon RP. Glucagon-like peptide-1 limits myocardial stunning following brief coronary occlusion and reperfusion in conscious canines. J Pharmacol Exp Ther. 2005;312(1):303-8.

13. Nikolaidis LA, Mankad S, Sokos GG, Miske G, Shah A, Elahi D, Shannon RP. Effects of glucagon-like peptide- 1 in patients with acute myocardial infarction and left ventricular dysfunction after successful reperfusion. Circulation. 2004;109(8):962-5.

14. Read PA, Hoole SP, White PA, Khan FZ, O'Sullivan M, West NE, Dutka DP. A pilot study to assess whether glucagon-like peptide-1 protects the heart from ischemic dysfunction and attenuates stunning after coronary balloon occlusion in humans. Circ Cardiovasc Interv. 2011;4(3):266-72.

15. McCormick LM, Hoole SP, White PA, Read PA, Axell RG, Clarke SJ, O'Sullivan $M$, West NE, Dutka DP. Pre-treatment with glucagon-like Peptide-1 protects against ischemic left ventricular dysfunction and stunning without a detected difference in myocardial substrate utilization. JACC Cardiovasc Interv. 2015;8(2):292-301.

16. Read PA, Khan FZ, Dutka DP. Cardioprotection against ischaemia induced by dobutamine stress using glucagon-like peptide- 1 in patients with coronary artery disease. Heart. 2012;98(5):408-13.

17. Basu A, Charkoudian N, Schrage W, Rizza RA, Basu R, Joyner MJ. Beneficial effects of GLP-1 on endothelial function in humans: dampening by glyburide but not by glimepiride. Am J Physiol Endocrinol Metab. 2007;293(5):E1289-95

18. Bose AK, Mocanu MM, Carr RD, Yellon DM. Myocardial ischaemia-reperfusion injury is attenuated by intact glucagon like peptide-1 (GLP-1) in the in vitro rat heart and may involve the p70s6K pathway. Cardiovasc Drugs Ther. 2007;21(4):253-6.

19. Loukogeorgakis SP, Williams R, Panagiotidou AT, Kolvekar SK, Donald A, Cole TJ, Yellon DM, Deanfield JE, MacAllister RJ. Transient limb ischemia induces remote preconditioning and remote postconditioning in humans by a K(ATP)-channel dependent mechanism. Circulation. 2007;116(12):1386-95.

20. Baan J, van der Velde ET, de Bruin HG, Smeenk GJ, Koops J, van Dijk AD, Temmerman D, Senden J, Buis B. Continuous measurement of left ventricular volume in animals and humans by conductance catheter. Circulation. 1984;70(5):812-23.

21. Yellon DM, Downey JM. Preconditioning the myocardium: from cellular physiology to clinical cardiology. Physiol Rev. 2003;83(4):1113-51.

22. Baptista J, Arnese M, Roelandt JR, Fioretti P, Keane D, Escaned J, Boersma E, di Mario C, Serruys PW. Quantitative coronary angiography in the estimation of the functional significance of coronary stenosis: correlations with dobutamine-atropine stress test. J Am Coll Cardiol. 1994;23(6):1434-9.

23. Bartko JJ. The intraclass correlation coefficient as a measure of reliability. Psychol Rep. 1966;19(1):3-11.

24. Hoole SP, Khan SN, White PA, Heck PM, Kharbanda RK, Densem CG, Clarke SC, Shapiro LM, Schofield PM, O'Sullivan M, et al. Remote ischaemic preconditioning does not attenuate ischaemic left ventricular dysfunction in humans. Eur J Heart Fail. 2009;11(5):497-505.

25. Green BD, Hand KV, Dougan JE, McDonnell BM, Cassidy RS, Grieve DJ. GLP-1 and related peptides cause concentration-dependent relaxation of rat aorta through a pathway involving KATP and CAMP. Arch Biochem Biophys. 2008:478(2):136-42.

26. Noyan-Ashraf MH, Momen MA, Ban K, Sadi AM, Zhou YQ, Riazi AM, Baggio LL, Henkelman RM, Husain M, Drucker DJ. GLP-1R agonist liraglutide activates cytoprotective pathways and improves outcomes after experimental myocardial infarction in mice. Diabetes. 2009:58(4):975-83.

27. Hausenloy DJ, Mocanu MM, Yellon DM. Cross-talk between the survival kinases during early reperfusion: its contribution to ischemic preconditioning. Cardiovasc Res. 2004;63(2):305-12.

28. Pyke C, Heller RS, Kirk RK, Orskov C, Reedtz-Runge S, Kaastrup P, Hvelplund A, Bardram L, Calatayud D, Knudsen LB. GLP-1 receptor localization in monkey and human tissue: novel distribution revealed with extensively validated monoclonal antibody. Endocrinology. 2014;155(4):1280-90

29. McCormick LM, Heck PM, Ring LS, Kydd AC, Clarke SJ, Hoole SP, Dutka DP. Glucagon-like peptide-1 protects against ischemic left ventricular dysfunction during hyperglycemia in patients with coronary artery disease and type 2 diabetes mellitus. Cardiovasc Diabetol. 2015;14:102.

30. Clarke SJ, McCormick LM, Dutka DP. Optimising cardioprotection during myocardial ischaemia: targeting potential intracellular pathways with glucagon-like peptide-1. Cardiovasc Diabetol. 2014;13:12.

31. Robinson LE, Holt TA, Rees K, Randeva HS, O'Hare JP. Effects of exenatide and liraglutide on heart rate, blood pressure and body weight: systematic review and meta-analysis. BMJ Open. 2013;3(1):e001986.

32. Ihara M, Asanuma H, Yamazaki S, Kato H, Asano Y, Shinozaki Y, Mori H, Minamino T, Asakura M, Sugimachi M, et al. An interaction between glucagon-like peptide-1 and adenosine contributes to cardioprotection of a dipeptidyl peptidase 4 inhibitor from myocardial ischemia-reperfusion injury. Am J Physiol Heart Circ Physiol. 2015;308(10):H1287-97.

33. Morrison RR, Tan XL, Ledent C, Mustafa SJ, Hofmann PA. Targeted deletion of A2A adenosine receptors attenuates the protective effects of myocardial postconditioning. Am J Physiol Heart Circ Physiol. 2007:293(4):H2523-9. 
34. Ban K, Noyan-Ashraf MH, Hoefer J, Bolz SS, Drucker DJ, Husain M. Cardioprotective and vasodilatory actions of glucagon-like peptide 1 receptor are mediated through both glucagon-like peptide 1 receptor-dependent and -independent pathways. Circulation. 2008;117(18):2340-50.

35. Ban K, Kim KH, Cho CK, Sauve M, Diamandis EP, Backx PH, Drucker DJ, Husain M. Glucagon-like peptide (GLP)-1 (9-36) amide-mediated cytoprotection is blocked by exendin (9-39) yet does not require the known GLP-1 receptor. Endocrinology. 2010;151(4):1520-31.

36. Cameron-Vendrig A, Reheman A, Siraj MA, Xu XR, Wang Y, Lei X, Afroze T, Shikatani E, El-Mounayri O, Noyan H, et al. Glucagon-like peptide 1 receptor activation attenuates platelet aggregation and thrombosis. Diabetes. 2016;65(6):1714-23.
37. Du X, Hu X, Wei J. Anti-inflammatory effect of exendin-4 postconditioning during myocardial ischemia and reperfusion. Mol Biol Rep. 2014:41(6):3853-7.

38. Broadhead MW, Kharbanda RK, Peters MJ, MacAllister RJ. KATP channel activation induces ischemic preconditioning of the endothelium in humans in vivo. Circulation. 2004;110(15):2077-82

\section{Submit your next manuscript to BioMed Central and we will help you at every step:}

- We accept pre-submission inquiries

- Our selector tool helps you to find the most relevant journal

- We provide round the clock customer support

- Convenient online submission

- Thorough peer review

- Inclusion in PubMed and all major indexing services

- Maximum visibility for your research

Submit your manuscript at www.biomedcentral com/submit 